\title{
Correction to: Microbiological Tools for Cultural Heritage Conservation
}

Amrita Kumari Panda, Rojita Mishra, and Satpal Singh Bisht

\section{Correction to: \\ Chapter 8 in: A. N. Yadav et al. (eds.), Microbial Biotechnology Approaches to Monuments of Cultural Heritage, https://doi.org/10.1007/978-981-15-3401-0_8}

The book was inadvertently published with an incorrect affiliation of the corresponding author Amrita Kumari Panda in Chapter 8 as Department of Microbiology, Gogate Jogalekar College, Ratnagiri, Maharashtra, India. The affiliation has now been corrected as Department of Biotechnology, Sant Gahira Guru University, Ambikapur, Chhattisgarh, India. 